\title{
PERFORMATIVIDADES DE GÊNEROS E DE SEXUALIDADES: IMPLICAÇÕES NA EDUCAÇÃO DAS JUVENTUDES
}

\author{
Carla Lisbôa GRESPAN ${ }^{1}$ \\ Cleber Gibbon RATTO ${ }^{2}$ \\ Miriam Pires Corrêa de LACERDA ${ }^{3}$
}

Resumo: O presente artigo tem por objetivo discutir as possibilidades de viabilizar as Políticas de Performatividades de gêneros e de sexualidades no âmbito escolar, através do diálogo entre as Teorias Pós-Estruturalistas, os Estudos Feministas e Queer e os dados apresentados no relatório do "Projeto de Estudo sobre Ações Discriminatórias no Âmbito Escolar" e da "Agenda Juventude Brasil". As Políticas de Performatividades vem se construindo nas fissuras e devem ser pauta nas discussões do cotidiano escolar, sendo um desses espaços de discussão, sem dúvida - o currículo. Acreditamos no seu potencial político que ao contemplar temáticas ligadas à cidadania e ao respeito às diferenças, poderá proporcionar condições de aprendizagem nas quais se recuperam as experiências da corporeidade, de pertencimento, de percepções e concepções de mundo, tornando-se espaço de acolhimento, de equidade de direitos e de oportunidades.

Palavras-chave: Políticas de performatividades. Educação. Juventudes. Gêneros. Sexualidades.

\section{Introdução}

$\mathrm{Na}$ história das sociedades modernas foram produzidos poderes/saberes sobre a sexualidade pautados por processos de controle e de incitamento. Estes processos, ao mesmo tempo em que, ampliaram a discussão teórica, mantiveram seu viés homofóbico, seja através da invisibilidade das diferentes práticas sexuais não heterossexuais, ou pela manutenção da naturalização do processo de correspondência entre sexo biológico gênero - prática sexual, a heteronormatividade.

No processo heteronormativo, o marcador social gênero ${ }^{4}$ atravessa o marcador sexualidade, e tem pautando as produções acadêmicas, principalmente, aquelas voltadas

\footnotetext{
1 Bolsista Capes/CNPq. Doutoranda em Educação. UNILASALLE - Centro Universitário La Salle. Canoas - RS - Brasil. 920100-000 - carla.grespan@ufrgs.br

${ }^{2}$ Bolsista de Produtividade do CNPq. PUC - Pontifícia Universidade Católica do Rio Grande do Sul. Coordenador Adjunto do Programa de Pós-Graduação em Educação. UNILASALLE - Centro Universitário La Salle. Canoas - RS - Brasil. 920100-000 -cleber.ratto@ unilasalle.edu.br

${ }^{3}$ PUC - Pontifícia Universidade Católica do Rio Grande do Sul - Pós-Graduação em Educação. Porto Alegre - RS - Brasil. 90619-900 - miriam.lacerda@ pucrs.br

4 Alinhados à Meyer (2004, p.15) consideramos que gênero remete a todas as formas de construção social, cultural e linguísticas implicadas com processos que diferenciam mulheres de homens, incluindo
} 
para a área da educação que apontam a escola como uma das instâncias pedagógicas de constituição do que é ser feminino ou masculino, de (re)afirmação dos papéis normatizados pela sociedade e das atitudes que os sujeitos tem que tomar, para se tornarem incluídos, reforçando as representações de determinados grupos e colocando outros na margem, na fronteira, na invisibilidade.

A concepção e organização da educação brasileira têm como base os padrões heteronormativos que valorizam e edificam um sujeito - homem, masculino, branco, de classe média/alta, jovem, "sarado" e heterossexual -, sendo que no cotidiano escolar, tais padrões são expressados por enunciações e comportamentos misóginos, sexistas e a homofóbicos (lesbofóbicos e transfóbicos).

O presente artigo pretende dialogar com os dados apresentados no relatório do Projeto de Estudo sobre Ações Discriminatórias no Âmbito Escolar ${ }^{5}$ (BRASIL, 2009) e na Agenda Juventude ${ }^{6}$ Brasil (BRASIL, 2014b) com os pressupostos teóricos das Teorias Pós-Estruturalistas e dos Estudos Feministas e Queer com o objetivo apontar possibilidades de viabilizar as políticas de performatividades de gênero e sexualidade no âmbito escolar.

\section{Escola e juventudes: atravessamentos de gêneros e sexualidades}

O Projeto de Estudo sobre Ações Discriminatórias no Âmbito Escolar foi uma pesquisa realizada, em 2008, pelo Instituto Nacional de Estudos e Pesquisas Educacionais (INEP) em parceria com a Fundação Instituto de Pesquisas Econômicas (FIPE), que abrangeu um estudo quantitativo por meio de uma survey ${ }^{7}$, aplicada em 500 escolas de todo o país tendo como público-alvo:

- 501 diretoras/es;

- 1.005 professoras/es que lecionam português ou matemática no Ensino Fundamental e Médio;

- 1.004 funcionárias/os entre secretária/o, porteira/o, orientador/a educacional, merendeira/o ou correlatos;

aqueles processos que produzem seus corpos, distinguindo-os e nomeando-os como corpos dotados de sexo, gênero e sexualidade.

${ }^{5}$ Relatório apresentado em 2009 e fruto de um convênio celebrado em 2008 entre o Instituto Nacional de Estudos e Pesquisas Educacionais (INEP) e a Fundação Instituto de Pesquisas Econômicas (FIPE) (BRASIL, 2009).

${ }^{6}$ Pesquisa nacional sobre perfil e opinião dos jovens brasileiros 2013 (BRASIL, 2014).

${ }^{7}$ Uma pesquisa survey é definida como uma “[...] coleta de informações sobre as características, ações ou opiniões sobre um grande grupo de pessoas, referidas como uma população". (TANUR apud PINSONNEAULT; KRAEMER, 1993, p.3). 
- 15.087 alunas/os dos anos finais do Ensino Fundamental, Médio e EJA;

- 1.002 pais/mães/responsáveis por alunos/as das séries anteriormente referidas, que sejam membros do Conselho Escolar ou da Associação de Pais e Mestres.

Considerando os temas abordados no âmbito da pesquisa: gênero, étnico-racial, socioeconômico, geracional, pessoas com deficiência, territorialidade e orientação sexual foram definidos como objetivos específicos avaliar percepções quanto:

- As situações de violência no âmbito escolar e familiar, especialmente as violências psicológica, física e de abuso e exploração sexual, e seus impactos em termos de atitudes e comportamentos das pessoas vitimadas;

- À incidência e intensidade de situações de discriminação de raça, de etnia, de gênero e de orientação sexual, ou ainda, por situações de conflito com a lei, das diversas populações-alvo do estudo;

- Ao reconhecimento e respeito à diversidade.

Os resultados desta pesquisa foram apresentados, em 2009, em um relatório:

[...] com o intuito de caracterizar a amostra do estudo em função do perfil demográfico de seus respondentes, descrever os comportamentos, atitudes, crenças e valores dos respondentes acerca dos diversos aspectos pesquisados que compõem as áreas temáticas de preconceito e discriminação abordadas neste estudo (étnico-racial, necessidades especiais, gênero, geracional, socioeconômica, territorial e orientação sexual) e de avaliar de maneira integrativa e simultânea, através de métodos estatísticos multivariados, a inter-relação existente entre as variáveis observadas e dimensões ou constructos inferidos que compõem as áreas temáticas mencionadas. (BRASIL, 2009, p.52).

Diferente da pesquisa anterior a Agenda Juventude Brasil, realizada em 2013 (BRASIL, 2014b), é uma das ações estratégicas da Secretaria Nacional de Juventude $(\mathrm{SNJ})$, que apresenta como uma de suas diretrizes o reconhecimento das/os jovens ${ }^{8}$ como sujeitos de direitos e de políticas públicas. A partir disso, é necessário conhecer as demandas, as opiniões e as realidades sociais, culturais, políticas e demográficas das juventudes brasileiras, não somente através do delineamento do perfil das mesmas, “[...] mas, principalmente, de acompanhar as tendências de comportamento e a opinião dos

\footnotetext{
${ }^{8}$ Segundo o Art. 227 da Constituição Brasileira (BRASIL, 2010), o Estatuto da Juventude e o Censo de 2010 (BRASIL, 2014a), jovem/segmento juvenil/juventude compreende o grupo etário de 15 a 29 anos.
} 
jovens, identificar as demandas por políticas públicas e aferir a ressonância de algumas respostas em curso.” (BRASIL, 2014b, p.11).

A pesquisa foi realizada entre abril e maio de 2013, através de entrevistas pessoais e domiciliares, estruturada em questionários (total de 161 perguntas e tempo médio de uma hora de aplicação). A amostra foi composta por 3.300 pessoas entre 15 a 29 anos, de 187 municípios das 27 Unidades da Federação, contemplando capital e interior, áreas urbanas e rurais, municípios de pequeno, médio e grande porte. Nesta amostra foi realizado um recorte de faixas etárias internas - 15 a 17 anos, 18 a 24 anos e 25 a 29 anos de idade - justificado pela adoção desse parâmetro pelas políticas públicas no país.

O relatório final da pesquisa subdivide os dados em oito grandes blocos temáticos:

1. Perfil e Condição Juvenil: juventude e idade, sexo, cor, religiões, jovens do campo e da cidade, configuração familiar, estratos socioeconômicos, escolaridade, condição de atividade;

2. Tecnologia de Informação e Comunicação: uso de computador, formas de uso e locais de acesso à internet; finalidades de uso da internet e do celular;

3. A Escola e a Formação Profissional: experiência educacional, percepções sobre a escola, formação profissional, cursos técnicos ou profissionalizantes;

4. O Mundo do Trabalho: o primeiro trabalho; trabalho e faixa etária, formalidade no trabalho, das jornadas de trabalho, procura de trabalho, jovens que não trabalham, percepções do mundo do trabalho;

5. Violência contra a Juventude Negra: experiências de discriminação;

6. Temas da Juventude e Percepções do País: realização pessoal, quais são os problemas que mais preocupam os jovens atualmente, diferentes âmbitos para discutir os assuntos, os problemas do Brasil que mais incomodam os/as jovens, o que os/as jovens mais valorizam no Brasil, expectativas com a vida, para o país e para a garantia de direitos, valores considerados fundamentais pelos/as jovens;

7. Vida Política: a política é importante, título de eleitor, os jovens podem mudar o mundo, valorização das formas de atuação e grau de participação;

8. Políticas para a Juventude: as ações do governo para a juventude, conhecimento de políticas por parte dos jovens, prioridades da ação governamental, ações para enfrentar a violência, melhor política para enfrentar a violência no país, políticas de saúde, mais e melhores políticas. 
Neste artigo os dados que serão analisados estão relacionados com os descritores: jovem/ns - juventude/s - escola - gênero - sexualidade. E como parâmetro etário para jovens/juventudes seguiremos a Lei $\mathrm{n}^{\circ}$ 12.852, de 5 de agosto de 2013 (BRASIL, 2013), que institui o Estatuto da Juventude, no parágrafo $1^{\circ}$ do seu art. $1^{\circ}$ que dispõe:

Art. $1^{\circ}$ Esta lei institui o Estatuto da Juventude e dispõe sobre os direitos dos jovens, os princípios e diretrizes das políticas públicas de juventude e o Sistema Nacional de Juventude (Sinajuve).

$\S 1^{\circ}$ Para os efeitos desta lei, são consideradas jovens as pessoas com idade entre quinze e vinte e nove anos de idade. (BRASIL, 2013).

A sociedade moderna atribuiu, para algumas instituições, a autoridade de definir, delimitar e moldar os padrões de normalidade, pureza ou sanidade, dentre essas a Escola tem cumprido seu papel de controle das juventudes no exercício do prazer, das possibilidades de experimentar os gêneros, de transformar e viver os corpos.

Os discursos sobre gênero e sexualidade produzidos e reproduzidos na escola procuram incentivar e reforçar representações de determinados sujeitos, invisibilizando outros, depositando-os na margem, na fronteira. Quando a instituição escolar coloca o processo heteronormativo em funcionamento acaba por impossibilitar as políticas de perfomatividades $^{9}$ de gêneros e de sexualidades, tornando a vida, de algumas pessoas da comunidade escolar, mais difícil de ser vivida.

Desta forma, algumas possíveis correlações e análise dos dados encontrados nestas duas pesquisas são de suma importância para a construção de práticas pedagógicas que visibilizem as múltiplas possibilidades de gêneros e sexualidades promovendo a diminuição da violência (física, moral e mental) contra as mulheres e pessoas LGBT(IQ) - Lésbicas, Gays, Transexuais/Travestis (Intersex e Queer) -, o respeito e a equidade de gênero.

\footnotetext{
${ }^{9}$ Butler (2014) argumenta que a "[...] identidade de gênero e a identidade sexual são produzidas por meio de repetidos enunciados performativos". Em outras palavras, "[...] a identidade cultural em geral é uma questão de performatividade". (SILVA, 2000, p.90).
} 


\section{Performatividades de gêneros e de sexualidades}

O século XIX nomeou, significou e, principalmente, normatizou a sexualidade. Segundo Foucault (1988), é um "aparato histórico"; é a história dos discursos que fizeram da sexualidade um corpo de conhecimento desenvolvido para organizar, modelar corpos e controlar comportamentos, criando o "saber sobre o prazer" e o “prazer de saber". Aqui surge o desvio da norma, homens e mulheres que desafiaram a heteronormatividade ${ }^{10}$, o sujeito homossexual.

Este processo que produziu os sujeitos homossexuais funciona como um sistema de marcação da diferença, "[...] aquilo que separa uma identidade da outra, estabelecendo distinções, frequentemente na forma de oposições" (WOODWARD, 2007, p.41), formando um sistema classificatório e de hierarquização social que na cultura ocidental contemporânea está fundado em um pensamento binário homossexual/heterossexual, feminino/masculino, branco/preto, pobre/rico, "normal"/diferente.

O sistema de diferenciação demarca as fronteiras entre a "norma" e o "desvio", nomeia o "normal" como centro e o "diferente" como a margem, é uma engrenagem do processo de significação que ocorre dentro das redes de poder/saber, fazendo com que o "diferente" tenha uma qualificação negativa, procurando fixar e estabilizar "a identidade" como hegemônica.

A criação dessas fronteiras identitárias não impede que o sujeito ultrapasse as mesmas, sendo necessário colocar em prática o processo de heteronormatividade. Como explica Louro,

A vigilância volta-se, então, explicitamente, para os corpos. Uma vigilância que é exercida não somente a partir do exterior, da obediência às regras, aos preceitos ou aos códigos, mas que é exercida pelo próprio indivíduo que, precocemente, aprende a se examinar, controlar, governar. (LOURO, 2000, p.69).

${ }^{10}$ Para Santos (apud FERREIRA, 1999) heteronormatividade resulta da aproximação de duas outras palavras conhecidas e de uso corrente em nossa cultura: hetero e norma. Hetero vem do grego e remete a diferente. Quando falamos em sexo nos referimos a heterossexual para dizer daqueles que tem "[...] afinidade, atração e/ou comportamentos entre indivíduos de sexo diferente" (SANTOS apud FERREIRA, 1999, p.1040). Norma nos direciona para o território daquilo que é considerado "[...] como base ou medida para avaliação de alguma coisa" (ibidem) dizendo também respeito à conduta, modelo, padrão. Assim, heteronormatividade conjuga a um só tempo heterossexualidade e padrões considerados legítimos. Ou seja: trata-se de "[...] um padrão de sexualidade que tem a qualidade ou a força de uma norma". (SANTOS, 2009, p.44). 
O corpo passa a ser o grande marcador social na contemporaneidade, porque é o operador do processo de diferenciação. O modo de viver e usar o corpo implica numa escolha - assumir, interpretar, (re)produzir uma infinidade de estilos e (re)organizar as normas. Maleável, mutante, transitório, ele é histórico e quando o mesmo começa a carregar o fardo da identidade fixa e cristaliza uma imagem no tempo e no espaço, criando uma representação social. Assim, as práticas corporais constituem relações de saber/poder, que produzem múltiplas discursividades de ser e estar no mundo.

Os discursos que buscam na suposta essência biologicista, como forma de fixar e estabilizar os sujeitos em uma identidade hegemônica discriminam seus corpos e suas práticas de gêneros e de sexualidades. Para Foucault (1988), o Dispositivo da Sexualidade foi instaurado para produzir discursos verdadeiros sobre o sexo, dentre os efeitos deste dispositivo está a experiência corporal generificada, ou seja, os poderes/saberes sobre o corpo produzem os discursos do verdadeiro homem, da verdadeira mulher.

As Teorias Pós-estruturalistas, os Estudos Feministas e, sobretudo, Estudos Queer, ${ }^{11}$ dissociam a pretensa ordem linear entre sexo, gênero e desejo sexual e possibilitam outro olhar sobre as relações de gênero e as sexualidades. Estes estudos colocam em pauta a discussão sobre as transformações sociais e biotecnológicas do corpo, seus atributos, suas sensações e seus desejos, no centro de interesse das produções acadêmicas. E apontam o corpo como o ponto mais frágil diante dos dispositivos de poder e de subjetivação que normatizam os gêneros, as sexualidades e as violências a partir de marcas biológicas que restringem em categorias identitárias e heteronormativas. O que Butler (2015) chama de violência normativa de gênero.

A educação brasileira foi concebida e organizada segundo os padrões da heteronormatividade, valorizando e edificando o adulto masculino, branco, de classe média e heterossexual. Tais padrões são acompanhados por suas enunciações e comportamentos que expressam a homofobia e o sexismo, sendo importante os resultados apresentados nas pesquisas para a construção de práticas pedagógicas de combater a homofobia, o sexismo e a misoginia no meio escolar.

${ }^{11}$ Nas palavras do sociólogo Seidman (apud MISKOLCI, 1996), o queer seria o estudo "[...] daqueles conhecimentos e daquelas práticas sociais que organizam a 'sociedade' como um todo, sexualizando heterossexualizando ou homossexualizando - corpos, desejos atos, identidades, relações sociais, conhecimentos, cultura e instituições sociais". (SEIDMAN apud MISKOLCI, 1996, p.13). 


\section{Relações de gênero e sexualidades: os marcadores sociais nas pesquisas que envolvem juventudes}

O "Projeto de Estudo sobre Ações Discriminatórias no Âmbito Escolar" realizado em 501 escolas brasileiras produziu um banco de dados que ao ser analisado tinha como

[...] intuito de caracterizar a amostra do estudo em função do perfil demográfico de seus respondentes, descrever os comportamentos, atitudes, crenças e valores dos respondentes acerca dos diversos aspectos pesquisados que compõem as áreas temáticas de preconceito e discriminação abordadas neste estudo (étnico-racial, necessidades especiais, gênero, geracional, socioeconômica, territorial e orientação sexual) e de avaliar de maneira integrativa e simultânea, através de métodos estatísticos multivariados, a inter-relação existente entre as variáveis observadas e dimensões ou constructos inferidos que compõem as áreas temáticas mencionadas. (BRASIL, 2009, p.53).

Nesse artigo temos as juventudes como recorte analítico e no tocante à estrutura etária os respondentes com menos de 30 anos de idade perfazem 6,8\% dos/as diretores/as de escolas, $20 \%$ de professore/as, 17,3\% de funcionários/as, 6,1\% de pais/mães/responsáveis e $86 \%$ de alunos/as. Assim, analisamos os dados dos/as alunos/as que estão distribuídos quantitativamente por regiões da seguinte maneira: região Sudeste $41 \%$ (1.478), região Nordeste 30\% (4.495), Sul 12\% (6.155), Norte 10\% (1.855) e Centro-Oeste com pouco mais de 7\% (1.101), tendo como foco as temáticas sobre gênero e sexualidade (BRASIL, 2009, p.56).

As questões relacionadas às atitudes sobre preconceito, bem como ao conhecimento de situações de discriminação presenciadas na escola (bullying) que compuseram o questionário da pesquisa foram elaboradas a partir de frases e expressões verbalizadas nos grupos focais, sendo que os resultados indicam que:

[...] o preconceito, é um elemento efetivamente presente no ambiente das escolas públicas do país. É importante notar que entre os públicos pesquisados, funcionários, pais e mães e, principalmente, os alunos, são os que apresentam os maiores níveis de preconceito, expressos por meio de suas atitudes em relação às frases pesquisadas. (BRASIL, 2009, p.69).

As frases foram organizadas em áreas temáticas (BRASIL, 2009) - étnico racial, deficiência, gênero, geracional, socioeconômica, territorial e orientação sexual -, e evidenciaram que os maiores percentuais de discriminação e bullying estão relacionados em primeiro lugar as relações de gênero (39\%) e em quarto à orientação sexual (26,7\%). 
Com maiores percentuais de concordância que expressam o preconceito em relação à orientação sexual (BRASIL, 2009, p.73) foram:

- "Os professores que não são gays são mais respeitados pelos estudantes" $44,9 \%$

- "Acho muito difícil aceitar a homossexualidade masculina" - 36,4\%;

- "Não evito, mas também não procuro chegar perto de homossexuais" - 35,3\%;

- "Uma lésbica é mais aceita na escola do que um gay" - 34,2\%.

Os índices mais baixos de aceitação de uma relação social (BRASIL, 2009, p.83) com uma pessoa homossexual são:

- "Aceitaria que meu(minha) filho(a) namorasse com ele(a). / Namoraria com ele(a)" - 1,2\%;

- "Aceitaria que meu(minha) filho(a) se casasse com ele(a). / Casaria com ele(a)" - 1,4\%;

- "Convidaria/aceitaria que estudasse em minha casa" - 14,1\%.

Em relação ao preconceito de gênero (BRASIL, 2009, p.77), entendido por nós como frases que expressam o sexismo e a misoginia, os maiores percentuais de concordância foram:

- "A mulher é mais habilidosa para cuidar da casa" - 60,6\%;

- "A mulher é melhor do que o homem na cozinha" - 52,6\%;

- "Existem trabalhos que devem ser realizados apenas por homens" - 46,3\%;

- "Existem trabalhos que devem ser realizadas apenas por mulheres" - 43,4\%.

O percentual de conhecimento de situações presenciadas na escola em função de discriminação e de bullying (atitudes de humilhação, de agressão física, de acusação injusta e outras situações) (BRASIL, 2009) enfrentados pelas/aos alunas/os, está relacionado em primeiro lugar à homossexualidade $(35,6 \%)$ e em quinto lugar ser mulher (19,2\%); pelas/os professoras/es aparecem em segundo e terceiro lugar, respectivamente, a homossexualidade (19,7\%) e ser mulher (15\%); pelas/os funcionárias/os em quarto lugar é por ser mulher $(13,4 \%)$ e em quinto pela homossexualidade (11\%). 
A pesquisa aponta algumas situações especificas de bullying, ou seja, a efetiva materialização do preconceito e da discriminação, por exemplo:

- As atitudes de agressão física enfrentada pelas/os alunos em terceiro lugar está à homossexualidade $(18,7 \%)$ e em quarto lugar por ser mulher (14,2\%); por professoras/es em primeiro lugar por ser mulher $(9,5 \%)$ e em terceiro pela homossexualidade $(7,7 \%)$; e as/os funcionárias/os em primeiro lugar por ser mulher $(7,4 \%)$ e em segundo pela homossexualidade $(6,7 \%)$.

- As acusações injustas sofridas pelas/os alunas/os o terceiro motivo é a homossexualidade $(15,4 \%)$ e o quinto por ser mulher $(11,1 \%)$; por professoras/es, empados em terceiro lugar aparecem a homossexualidade e ser mulher (8,2\%); e pelas/os funcionárias/os apontam ser mulher em quarto lugar (7,5\%) e a homossexualidade em quinto $(6,8 \%)$.

- O tratamento com desprezo ou falta de consideração enfrentado por alunas/os o terceiro motivo é a homossexualidade (25,5\%) e o oitavo por ser mulher (12,7\%); por professoras/es, empados em terceiro lugar aparecem a homossexualidade e ser mulher (8,2\%); e pelas/os funcionárias/os apontam ser mulher em quarto lugar (7,5\%) e a homossexualidade em quinto $(6,8 \%)$.

Os dados organizados por nível de ensino (BRASIL, 2009) indicam que as/os alunas/os concordam com frases que expressam atitudes preconceituosas em relação a gênero e a orientação sexual nas seguintes percentuais: no penúltimo ano do Ensino Fundamental - primeiro lugar para gênero $42 \%$ e terceiro lugar para orientação sexual 30\%; no último ano do Ensino Médio - segundo lugar para gênero 34\% e quarto lugar para orientação sexual 23\%; no Ensino Fundamental Modalidade EJA - primeiro lugar gênero $42 \%$ e quinto lugar para orientação sexual 28\%; e Ensino Médio Modalidade EJA - segundo lugar gênero $36 \%$ e quarto lugar para orientação sexual $24 \%$.

Os índices percentuais de atitude preconceituosa, de distância social e de conhecimento da ocorrência de situações de bullying por gênero ou por orientação sexual, levando em conta o porte da escola (BRASIL, 2009) são: pequena até 600 alunas/os - primeiro lugar gênero $42 \%$ e quarto lugar para orientação sexual 28\%; média de 601 a 1000 alunas/os - primeiro lugar gênero 38\% e quarto lugar para orientação sexual 27\%; e grande mais de 1000 alunos - segundo lugar gênero 36\% e quarto lugar para orientação sexual 25\%. Já as situações de bullying em relação aos grupos sociais mulher e homossexual são: pequena até 600 alunas/os - segundo lugar 9\%; média de 
601 a 1000 alunas/os - segundo lugar homossexual 12\% e terceiro lugar mulher 9\% e; e grande mais de 1000 alunos - segundo lugar homossexual 11\% e terceiro lugar mulher $9 \%$.

De acordo com a localização da escola (BRASIL, 2009), as áreas temáticas de preconceito de gênero e orientação sexual obtiveram os seguintes índices: área urbana da capital - segundo lugar gênero 36\% e quinto lugar orientação sexual 26\%; área urbana do interior - primeiro lugar gênero 39\% e quarto lugar orientação sexual 27\%; e área rural - primeiro lugar gênero $43 \%$ e quarto lugar orientação sexual 30\%. E em relação aos grupos sociais os índices corresponderam a: área urbana da capital primeiro lugar homossexual 13\% e terceiro lugar mulher 10\%; área urbana do interior segundo lugar homossexual 10\% e terceiro lugar mulher 9\%; e área rural - terceiro lugar mulher $10 \%$ e quinto lugar homossexual $8 \%$.

As médias para o índice percentual de concordância com frases que expressam atitudes preconceituosas por região do país (BRASIL, 2009), em relação as áreas temáticas ficaram em: região Sudeste - segundo lugar gênero 37\% e quarto lugar orientação sexual 29\%; região Nordeste - primeiro lugar gênero $44 \%$ e quarto lugar orientação sexual 29\%; Sul - segundo lugar gênero 37\% e quarto lugar orientação sexual 29\%; Norte primeiro lugar gênero 39\% e quarto lugar orientação sexual 27\%; e região Centro-Oeste - segundo lugar gênero 38\% e quarto lugar orientação sexual $27 \%$. Em relação aos grupos sociais o índice ficou em: região Sudeste - segundo lugar homossexual $10 \%$ e terceiro lugar mulher 8\%; região Nordeste - segundo lugar homossexual $12 \%$ e terceiro lugar gênero $10 \%$; região Sul - terceiro lugar homossexual $8 \%$ e quarto lugar mulher gênero 7\%; e região Centro-Oeste - terceiro lugar homossexual $11 \%$ e quarto lugar mulher $10 \%$.

Os índices percentuais que levam em conta o grau de acesso aos meios de informação são: muito baixo - primeiro lugar gênero $43 \%$ e quarto lugar para orientação sexual 28\%; baixo - primeiro lugar gênero $41 \%$ e quarto lugar para orientação sexual $28 \%$; e alto - primeiro lugar gênero $35 \%$ e terceiro lugar para orientação sexual 24\%. Já as situações de bullying em relação aos grupos sociais mulher e homossexual são: muito baixo - segundo lugar mulher $9 \%$ e terceiro homossexual $8 \%$; baixo - segundo lugar homossexual $12 \%$ e terceiro lugar mulher $9 \%$ e; e alto - terceiro lugar homossexual $11 \%$ e quarto lugar mulher $9 \%$.

A média percentual das frases que relacionavam as atitudes de alunas/os e as dimensões temáticas (BRASIL, 2009, p.181) foi: 
- Dimensão Gênero: "Há funções na escola que só podem ser desempenhadas por um gênero específico" - 23,3\%; "Há trabalhos que só podem ser realizados por um gênero específico" - 44,9\%; "Trabalho doméstico é tarefa da mulher" $-56,6 \%$. Totalizando 39\%, maior média de preconceito das dimensões temáticas;

- Dimensão Orientação Sexual: "Homossexuais não devem participar de ambiente escolar de heterossexuais" - 18\%; "Não aceitação da homossexualidade" $37,7 \%$. Dimensão que totalizou $26,7 \%$ ficando em quarto lugar.

Os dados que relacionam frases das dimensões temáticas com a faixa etária (BRASIL, 2009, p.197) de todas/os respondentes compuseram as seguintes médias percentuais, nas faixas etárias correspondentes as juventudes (15 a 29 anos):

- Dimensão Gênero: "Há funções na escola que só podem ser desempenhadas por um gênero específico" - de 15 a 19 anos 23,9\% e 20 a 29 anos 22,5\%; "Há trabalhos que só podem ser realizados por um gênero específico" - de 15 a 19 anos 44,4\% e 20 a 29 anos 44,2\%; "Trabalho doméstico é tarefa da mulher" - de 15 a 19 anos $56,1 \%$ e 20 a 29 anos 55,5\%. Perfazendo a maior média de preconceito das dimensões temáticas 15 a 19 anos 39\% e 20 a 29 anos 38,2\%;

- Dimensão Orientação Sexual: "Homossexuais não devem participar de ambiente escolar de heterossexuais" - de 15 a 19 anos $18,4 \%$ e 20 a 29 anos 14,9\%; "Não aceitação da homossexualidade" - de 15 a 19 anos 38,7\% e 20 a 29 anos 36,7\%. A média do percentual dessa dimensão totalizou entre 15 a 19 anos 27,4\% ficando em quarto lugar e entre 20 a 29 anos $24,6 \%$ ficando em quinto lugar.

A média percentual para os dados que relacionaram os motivos de bullying e faixa etária (BRASIL, 2009) entre 15 e 29 anos foram: de 15 a 19 anos em terceiro lugar por ser homossexual $12 \%$ e quinto lugar por ser mulher 9,3\%; de 20 a 29 anos em terceiro lugar por ser homossexual $8,6 \%$ e quarto lugar por ser mulher $7,8 \%$.

$\mathrm{O}$ grupo de alunas/os que responderam à pesquisa apresentou de um lado os maiores coeficientes de correlação entre as atitudes preconceituosas e o conhecimento declarado de situações discriminatórias na escola. E de outro as menores correlações entre a distância social e o conhecimento de situações de bullying. Assim podemos apontar que o fator com maior influência para o conhecimento da ocorrência de situações de bullying nas escolas é a atitude preconceituosa das/os alunas/os. 
A pesquisa finaliza apontando como fato mais preocupante que:

[...] o preconceito e a discriminação não raramente resultam em situações em que pessoas são humilhadas, agredidas e acusadas injustamente simplesmente pelo fato de fazerem parte de algum grupo social específico. Nota-se que estas práticas discriminatórias têm como principais vítimas os alunos, especialmente negros, pobres e homossexuais. Apesar do fato de que os alunos são as maiores vítimas, as práticas discriminatórias na escola também vitimam professores e funcionários com preocupante incidência. Entre os professores vitimados, os que mais sofrem os efeitos de práticas discriminatórias, de acordo com o conhecimento dos respondentes, são os professores mais velhos, os homossexuais e as mulheres entre os funcionários, as maiores vítimas são os pobres, idosos e negros. (BRASIL, 2009, p.352).

A Agenda Juventude Brasil 2013 (BRASIL, 2014b) é uma pesquisa com um único público alvo, jovens de 15 a 29 anos, perfil etário fundamentado no Censo de 2010 (BRASIL, 2014a) que apontou a juventude como equivalente a 1/1/4 da população do país. Inferindo sobre a extensão do arco etário justifica os parâmetros de intervalos de faixas etárias - 15 a 17 anos, 18 a 24 anos e 25 a 29 anos de idade - como parâmetro adotado por políticas públicas no país.

Os dados levantados pela pesquisa têm como principal objetivo a identificação das demandas da juventude para construção de políticas públicas. Para isso preocupouse em traçar o perfil, acompanhar as tendências de comportamento e a opinião da atual juventude brasileira, tendo como base as pesquisas "Perfil da Juventude Brasileira" de 2003, “Juventudes Brasileiras” de 2004 e "Juventudes Sul-Americanas” de 2008.

Organizada em blocos temáticos referentes à condição juvenil, educação, trabalho, saúde (envolvendo os temas de drogas e de sexualidade), cultura e lazer, participação política e violência, esta pesquisa foi realizada em todo o território nacional, sendo representativa para o meio urbano e rural [...] (BRASIL, 2014b, p.9).

O recorte dos dados que utilizamos dessa pesquisa segue o critério das questões que envolvem a instituição escolar, as relações de gênero e as sexualidades, com o atravessamento dos marcadores: corpo, saúde e violência. A partir disso, os primeiros dados relevantes são que a faixa etária de 15 a 17 anos de idade tem como atividade mais importante o estudo com 80\%; de 18 a 24 anos as atividades de estudo caem vertiginosamente para 33\%, dando lugar às atividades remuneradas (trabalho) 54\%; de 25 a 29 anos a atividade mais importante passa a ser o trabalho com $72 \%$ e as atividades 
de estudo caem para 14\%. E o segundo dado relevante e que podemos fazer uma relação com a prática ou não da atividade sexual, aponta que desde a faixa etária dos 15 aos 17 anos as/os jovens já têm sexualidade ativa, mesmo que a pesquisa somente tenha tomado como parâmetro o casamento e a prole (BRASIL, 2014b).

$\mathrm{Na}$ variável que relaciona a localização geográfica (urbana ou rural) e os meios midiáticos, a televisão aparece como primeira mídia tanto para as juventudes urbanas quanto rurais, respectivamente $81,4 \%$ e $92,6 \%$ (TV aberta) e 10,8\% e 1,4\% (TV fechada). A internet aparecerá em segundo lugar com 4,9\% e 1,8\%, mesmo com essa baixa porcentagem em relação a televisão, $80 \%$ das/os entrevistadas/os utilizam computador e/ou internet e desses $75 \%$ utiliza ambos, sendo que $55 \%$ acessa a rede com maior frequência em casa e como principal finalidade de uso os sites de relacionamento (redes sociais) com 56\% das respostas (BRASIL, 2014b).

Os cruzamentos dos dados de escolaridade, possuir ou não um celular e sua utilização identificamos que as/os entrevistadas/os que frequentaram a Educação Básica (Ensino Fundamental e Médio) cursou em escola da rede pública de ensino (entre 60 a 70\%). As/os jovens que possuem o Ensino Fundamental Incompleto 78\% possui celular e o utiliza para fazer e ou receber ligações telefônicas (75\%); quem está tem ou está cursando o Ensino Fundamental Completo $83 \%$ possui celular e utilizam para fazer e ou receber ligações telefônicas (79\%) e para comunicar-se via mensagens de texto / SMS (53\%); as/os com escolaridade de Ensino Médio Incompleto 94\% tem celular e diversifica sua utilização em fazer e ou receber ligações telefônicas (94\%), comunicarse via mensagens de texto / SMS (67\%) e ouvir música (40\%); no Ensino Médio Completo $94 \%$ possuem celular, tendo como principais utilizações em fazer e ou receber ligações telefônicas (93\%), comunicar-se via mensagens de texto / SMS (57\%), ouvir música (31\%); no Ensino Superior ou mais $100 \%$ possuem celular, tendo uma maior variedade de utilização - fazer e ou receber ligações telefônicas (99\%), comunicar-se via mensagens de texto / SMS (60\%), ouvir música (31\%), buscar informações pela internet (36\%) e conectar-se a redes sociais (25\%) (BRASIL, 2014b).

Relacionando os motivos de interrupção dos estudos segundo o sexo biológico das/os jovens entrevistadas/os, podemos apontar que a falta de vontade de estudar é expressiva nos dois casos (30\%); já a dificuldade de conciliar com o trabalho (5\%) e para cuidar de um parente (20\%), só ocorre entre as mulheres; enquanto que somente os homens apontam a discriminação (3\%), a falta de vaga (12\%) e o casamento (5\%); a 
falta de dinheiro e cuidar da prole parecem ter mais peso para os homens (25\% e 13\%) do que para as mulheres (5\% e 8\%) (BRASIL, 2014b).

A pesquisa indica que $40 \%$ das/os jovens brasileiros possui uma jornada de trabalho de 40h semanais; "[...] que homens jovens possuem $25 \%$ mais chances de ter uma ocupação formal do que as mulheres jovens" (BRASIL, 2014b, p.52); que as mulheres tem mais dificuldades na procura do trabalho por faltar experiência (43\%); e a parcela de jovens que não estão nem trabalhando, nem estudando "[...] se concentra entre as jovens que são mães, com baixa renda, e que adiam a entrada ou se retiram do mercado de trabalho restringindo sua atividade à esfera da reprodução". (BRASIL, 2014b, p.56).

As perguntas direcionadas aos assuntos (BRASIL, 2014b, p.72) que os jovens gostariam de discutir:

- Com seus pais ou responsáveis: a educação e o futuro profissional (45\%), a violência (32\%), drogas (31\%), desigualdade social e pobreza (27\%), religião (24\%), cidadania e direitos humanos $(21 \%)$;

- Com os amigos: drogas (41\%), sexualidade (31\%), violência (30\%), educação e futuro profissional (29\%), relacionamentos amorosos (26\%), racismo (23\%) e artes $(21 \%)$;

- Com a sociedade em geral: desigualdade social e pobreza (40\%), drogas (38\%), violência (38\%), política (33\%), cidadania e direitos humanos $(32 \%)$, educação e futuro profissional (25\%), racismo (25\%) e meio ambiente e desenvolvimento sustentável (24\%).

$\mathrm{Na}$ análise dos assuntos importantes para serem discutidos os dados apontam que as temáticas que envolvem violência e drogas devem ser discutidas em todos os âmbitos, possivelmente por ser um assunto próximo do cotidiano das juventudes e também uma questão enfrentada por toda a sociedade, mas algumas variações são assinaladas:

[...] a questão do estudo e do futuro profissional é o assunto mais citado como importante para ser debatido com a família, enquanto ocupa apenas a $6^{\text {a }}$ posição como assunto de relevância social. Na sociedade é o tema da desigualdade e da pobreza que ganha expressiva relevância, aparecendo pouco como assunto para discutir com amigos, mas não tão longe das prioridades para debater com a família. Por outro lado, sexualidade é francamente um tema para 
debater com amigos, ocupando pouco espaço de interesse como tema para a família ou a sociedade. (BRASIL, 2014b, p.73).

As questões que propuseram levantar os problemas que mais incomodam as/os jovens apontaram a corrupção (67\%), o poder dos traficantes (46\%), a grande desigualdade entre ricos e pobres $(42 \%)$ e o racismo e outras formas de discriminação (34\%), sendo que a desigualdade social aparece como tema central, mas as formas de enfrentamento para a mesma aparecerão mais nas/os jovens dos estratos mais pobres. Em contrapartida essas/es jovens citaram como pontos positivos do país as possibilidades de estudo (63\%) e a liberdade de expressão (55\%) (BRASIL, 2014b).

Em relação a expectativa para com suas vidas são mais otimistas quanto mais próximo da sua esfera cotidiana, já em relação ao mundo são mais pessimistas que otimistas. Isso se confirma com os índices das respostas referentes ao Brasil 44\% vai melhorar, ao seu bairro aumenta para $53 \%$ e a sua vida $94 \%$ devido perspectivas positivas quanto as possibilidades de trabalho e educação.

As perguntas relativas há quais elementos (BRASIL, 2014b, p.79) são mais importantes para: “[...] sua vida presente - apoio da família 75\%; para melhorar de vida - esforço pessoal 68\%; e para garantir direitos - políticas do governo 47\%". O que se ajusta as respostas sobre um mundo ideal e os valores que julgavam serem os mais importantes:

[...] o temor a deus $40 \%$; o respeito às diferenças $39 \%$; e igualdade de oportunidades $33 \%$, sendo que o respeito às diferenças terá um peso maior que o temor a deus nas faixas etárias de 15-17 e 18-24, e fica empatado em $44 \%$ quando extraímos os dados respondidos pelas mulheres. E que corrobora com os índices sobre a favor ou contra a adoção de crianças por casais de mesmo sexo (51\%) e a reserva de cotas raciais e étnicas nas universidades (56\%). (BRASIL, 2014b, p.80).

Um fator levantado pela pesquisa, bem relevante em relação a sexualidade, está ligado a relação entre renda e adoção por casais homossexuais, onde os dados indicam que:

Os jovens pertencentes aos estratos de renda domiciliar per capita alta são mais fortemente contrários a que casais homossexuais adotem crianças do que os segmentos de renda inferior. Enquanto $42 \%$ dos entrevistados de segmentos ricos posicionam-se contra a adoção, são $36 \%$ dos estratos médios e $34 \%$ dos jovens de baixa renda que compartilham essa opinião. Interessante notar que a renda não produz 
variação significativa entre aqueles que se declaram favoráveis a esse direito dos homossexuais. (BRASIL, 2014b, p.81).

Outro dado a ressaltar é que as juventudes não demonstram interesse em formas de associativismo e participação política ou social, as/os que nunca participaram representam 54\% e destes $15 \%$ não participariam de associações, entidades e grupos, por exemplo: partido político (88\%); cooperativa (74\%); entidade ou grupo de mídias livres ou alternativas (66\%); associação de defesa do consumidor (63\%); grupo ou associação de trabalho voluntário não religioso (60\%); entidade ou movimento em defesa de grupos discriminados (60\%) (BRASIL, 2014b).

As questões que envolvem relações de gênero e sexualidades são mais enfatizadas nas perguntas sobre as formas de enfrentamento da violência e promoção da saúde, onde $32 \%$ das mulheres recomendaram como uma das formas de enfrentar a violência seria a promoção do desarmamento e 97\% das/os entrevistadas/os valorizam as políticas públicas para prevenção e/ou atendimento a doenças sexualmente transmissíveis e Aids.

\section{Considerações finais}

As relações analíticas que podemos produzir a partir dos dados dessas pesquisas são inúmeras dependendo dos recortes temáticos e pressupostos teóricos utilizados. Nesse artigo tratamos das relações analíticas que partem dos descritores jovem/ns juventude/s - escola - gênero - sexualidade e dos pressupostos teóricos as Teorias PósEstruturalistas e os Estudos Feministas e Queer.

A partir dos dados e das análises produzidas pelo Projeto de Estudo sobre Ações Discriminatórias no Âmbito Escolar podemos inferir que o maior peso das atitudes, crenças e valores que expressam o preconceito referem-se às áreas temáticas de gênero e de orientação sexual; que o maior peso no construto de distância social foi em relação ao grupo social das/os homossexuais; que os valores do índice percentual de distância social são superiores aos observados para as medidas de atitudes preconceituosas, indicando que não aceitam a diversidade como parecem perceber e possuem intenções comportamentais que efetivamente denotam discriminação; e que o bullying em relação a orientação sexual ocorre nas escolas com maior número de alunas/os e que demostraram menores índices nas avaliações da Prova Brasil de 2007.

Os discursos que se fazem representar nas falas e práticas de alunas/os no cotidiano escolar fazem com que seus protagonistas sejam interpelados e/ou subjugados 
a padrões de gênero e de sexualidade. Sob a ótica de Foucault (2009) o discurso como elemento ativo das estratégias de poder-saber constrói e veicula representações de mundo e de seus sujeitos, com o intuito de naturalizar, classificar e hierarquizar (permitido/proibido, certo/errado, adequado/inadequado, normal/diferente, incluíd@/excluíd@).

As temáticas que envolvem misoginia, sexismo e homofobia tem um espaço diminuto nos currículos escolares e quando tratados estão relacionados ao viés da saúde e violência. Isso advém da utilização dos discursos biologicistas que naturalizam as vidas, fixando em uma única identidade, uma única possibilidade de ser vivida, a heterossexualidade, reafirmando as atitudes discriminatórias e de bullying em relação as performatividades de gêneros e de sexualidades.

Os dados da "Agenda Juventude Brasil 2013" (BRASIL, 2014b) apesar de indicarem que um dos pontos positivos do país é a liberdade de expressão e que um dos valores mais importantes seja o respeito as diferenças, muitos jovens ainda são contra a adoção de crianças por casais homossexuais; não há menção sobre bullying ou qualquer outra violência direcionada as mulheres e as/aos homossexuais.

A temática sobre sexualidade foi tratada pelo viés do casamento e da procriação e as questões de equidade de gênero foram ligadas as relações de trabalho, ou seja, dificuldade em encontrar emprego por parte das mulheres estaria ligada a falta de experiência e/ou procriação.

Enquanto a pesquisa realizada em 2009 (BRASIL, 2009) aponta que as/os jovens são os que mais sofrem e também produzem o bullying na escola direcionando a discriminação e violência as mulheres e homossexuais. Já a pesquisa realizada em 2013 (BRASIL, 2014b), causou estranhamento, pois público alvo as juventudes, silencia sobre as questões de equidade de gênero e de respeito as sexualidades.

Segundo Butler (2010), a sexualidade não pode ser entendida como prédiscursiva, as condições de produção são necessárias no entendimento da construção dos sujeitos em consonância com a construção do cenário onde atuam. Os sujeitos são construídos e se constroem num determinado lócus, que também não está dado.

Dentro da lógica binária do par homem-mulher, as questões relacionadas à homossexualidade causam desconforto. As/os homossexuais estão inseridas/os no rol dos sujeitos abjetos, das aberrações. Para Louro (2003, p.2) os corpos, como também as sexualidades e os gêneros, “[...] são descritos, compreendidos, explicados, regulados, 
saneados e educados, por muitas instâncias, através das mais variadas táticas, estratégias e técnicas".

A cultura contemporânea nos apresenta um mosaico, novos desenhos e configurações de gêneros e de sexualidades que precisa ser visto como um processo de desconstrução e descontinuidade de valores, verdades e estruturas. O sujeito corporificado não é sempre o mesmo o tempo todo, o aparato que constrói o corpo não consegue fixá-lo, ora ele é assujeitado, ora consegue fugir.

E são nessas linhas de fuga, nessas fissuras que as Políticas de Performatividades se constroem e devem ser pauta nas discussões do cotidiano escolar para que se possam produzir práticas que eliminem a discriminação, que resulta em humilhação e agressão (psicológica e física).

Um desses espaços de discussão é sem dúvida, o currículo. Quando entendido como um texto no qual construções linguísticas estão visceralmente implicadas na produção da realidade, não há como desconhecer o potencial político do mesmo. Concebido, como "prática de significação" o currículo abre outras possibilidades de ver e de pensar o mundo e sobre o mundo e, nessa medida, pode vir a assegurar a produção, a negociação e transformação dos saberes veiculados na e pela escola.

Se assim acreditamos, o currículo escolar ao contemplar temáticas ligadas à cidadania (atitudes e valores), ao respeito as diferenças, priorizando as discussões sobre homofobia, misoginia e sexismo, proporciona condições de aprendizagem nas quais se recuperam as experiências da corporeidade, de pertencimento, de percepções, e concepções de mundo, tornando-se espaço de acolhimento e reflexão de informações, de dúvidas, de valores, de atitudes e de equidade de direitos e oportunidades.

\section{PERFORMATIVITY OF GENDER AND SEXUALITIES: THE IMPLICATIONS IN THE EDUCATION OF YOUTHS}


Abstract: This article aims to discuss the possibilities of bringing about gender and sexuality Performativities Policies in schools, through dialogue between the Poststructuralists Theories, Feminist and Queer Studies and the data presented in the report "Study Project on Discriminatory actions in School Scope" and "Agenda Youth Brazil". The Performativities Policies has been building in the cracks and should be the agenda in discussions of everyday school life, being one of those spaces for discussion, no doubt - the curriculum. We believe in its political potential to contemplate themes related to citizenship and respect for differences, can provide learning conditions in which recover the experiences of corporeality, of belonging, perceptions and conceptions of the world, becoming host space, equal rights and opportunities.

Key words: Performativities policies. Education. Youths. Gender. Sexualities.

\section{REFERENCIAS}

BRASIL. Instituto Brasileiro de Geografia e Estatística - IBGE. Censo 2010. Brasília IBGE, 2014a. Disponível em: <http://censo2010.ibge.gov.br/>. Acesso em: 24 fev. 2016.

BRASIL. Secretaria Nacional da Juventude. Agenda Juventude Brasil: pesquisa nacional sobre perfil e opinião dos jovens brasileiros. Brasília: SNJ - Secretaria Nacional da Juventude, 2014b. Disponível em:

$<$ https://issuu.com/participatorio/docs/agenda_juventude_brasil__pesquisa_/1?e=12152407/10902032>. Acesso em: 24 fev. 2016.

BRASIL. Lei nº 12.852 - Estatuto da Juventude. Diário Oficial da União, Brasília, DF, Seção 1, 2 de ago. 2013. p. 1. Disponível em:

<http://www.planalto.gov.br/ccivil_03/_Ato2011-2014/2013/Lei/L12852.htm>. Acesso em: 24 fev. 2016.

BRASIL. Constituição (1988). Artigo no 227 com redação dada pela Emenda Constitucional $\mathbf{n}^{\mathbf{0}} 65$ de 2010. Brasília Senado Federal, 2010. Disponível em: <http://www.planalto.gov.br/ccivil_03/Constituicao/Constituicao>. Acesso em: 24 fev. 2016.

BRASIL. Projeto de estudo sobre ações discriminatórias no âmbito escolar, organizadas de acordo com áreas temáticas, a saber, étnico-racial, gênero, geracional, territorial, necessidades especiais, socioeconômica e orientação sexual. São Paulo: FIPE, 2009. Disponível em:

<http://portal.mec.gov.br/dmdocuments/relatoriofinal.pdf>. Acesso em: 24 fev. 2016.

BUTLER, J. Relatar a si mesmo: crítica da violência ética. Tradução de R. Bettoni. São Paulo: Autêntica, 2015.

BUTLER, J. Repensar la vulnerabilidad y la resistencia. Alcalá de Henares: [s.n.], 2014. Disponível em: 
<http://www.cihuatl.pueg.unam.mx/pinakes/userdocs/assusr/A2/A2_2195.pdf >. Acesso em: 20 mar. 2016.

BUTLER, J. Problemas de gênero: feminismo e subversão da identidade. Rio de Janeiro: Editora Civilização Brasileira, 2010.

FERREIRA, A. B. H. Novo Aurélio século XXI: o dicionário da língua portuguesa. 3.ed. rev. e ampl. Rio de Janeiro: Nova Fronteira, 1999.

FOUCAULT, M. A ordem do discurso. Tradução de L. F. A. Sampaio. 18.ed. São Paulo: Edições Loyola, 2009.

FOUCAULT, M. História da sexualidade I: a vontade de saber. Rio de Janeiro: Edições Graal, 1988.

LOURO, G. L. Corpos que escapam. Labrys, Estudos Feministas, [S.1.], n.4, ago./dez. 2003. Disponível em: <http://vsites.unb.br/ih/his/gefem/labrys4/textos/guacira1.htm>. Acesso em: 12 jun. 2011.

LOURO, G. L. Corpo, escola e identidade. Educação e Realidade, Porto Alegre, v.25, n.2, p.59-76, jul./dez. 2000.

MEYER, D. E. Teorias políticas de gênero: fragmentos históricos e desafios atuais. Revista Brasileira de Enfermagem, Brasília, v.57, n.1, p.13-18, jan./fev. 2004. Disponível em: <http://www.scielo.br/pdf/reben/v57n1/a03v57n1.pdf>. Acesso em: 24 mar. 2016.

MISKOLCI, R. A teoria queer e a sociologia: o desafio de uma analítica da normalização. Sociologias, Porto Alegre, n.21, p.150-182, jun. 2009. Disponível em: $<$ http://www.scielo.br/scielo.php?script=sci_arttext\&pid=S151745222009000100008\&lng=en\&nrm=iso >. Acesso em: 27 mar. 2016.

PINSONNEAULT, A.; KRAEMER, K. Survey research methodology in management information systems: an assessment. Journal of Management Information Systems, Armonk, v.10, n.2, p.75, 1993.

SANTOS, L. H. S. Heteronormatividade e educação. In: PENALVO, C.; BERNARDES, G. (Org). Tá difícil falar de sexo na escola. Porto Alegre: SOMOS, 2009. p.24-35.

SILVA, T. T. Teoria cultural e educação: um vocabulário crítico. Belo Horizonte: Autêntica, 2000.

WOODWARD, K. Identidade e diferença: uma introdução teórica e conceitual. In: SILVA, T. T. (Org). Identidade e diferença: a perspectiva dos estudos culturais. Petrópolis: Vozes, 2007. p.7-72. 